\title{
Cerebrospinal fluid plasminogen activator inhibitor-1 in patients with neurological disease
}

\author{
F O T Akenami, M Koskiniemi, M Färkkilä, A Vaheri
}

\begin{abstract}
Aim-To study cerebrospinal fluid (CSF) concentrations of plasminogen activator inhibitor type-1 (PAI-1) in patients with neurological disease.

Methods-CSF PAI-1 concentrations were measured in 51 patients with neurological disease and 20 reference subjects using an ELISA. The patient group comprised three patients with viral meningitis, 20 with encephalitis, nine with acute lymphoblastic $(n=7)$ and myeloid $(n=2)$ leukaemia (with central nervous system involvement), and 19 with multiple sclerosis.
\end{abstract}

Results-Raised PAI-1 concentrations were observed in patients with leukaemia, encephalitis and multiple sclerosis. There was no difference in the mean concentrations of PAI-1 in patients with meningitis when compared with the reference subjects. The highest mean (SEM) PAI-1 concentration was found in patients with leukaemia $(1.28(0.36) \mathrm{ng} / \mathrm{ml})$, and the next highest in those with encephalitis (1.19 $(0.20) \mathrm{ng} / \mathrm{ml})$. These values were much higher than those in patients with viral meningitis. In a previous report, raised CSF tissue-type plasminogen activator (tPA) activities were detected in patients with multiple sclerosis, leukaemia and encephalitis, with mean activities in decreasing order. PAI-1 concentrations in the same patients were the reverse of their corresponding tPA activities, being higher in those with leukaemia and encephalitis, than in patients with multiple sclerosis. There was no association between CSF PAI-1 concentrations and age in either patients or controls. Similarly, there was no association between CSF PAI-1 concentrations and urokinase-type plasminogen activator (uPA).

Conclusions-Raised CSF PAI-1 concentrations may be used as a non-specific marker of neurological disease. Moreover, PAI-1 may play an important role in regulating the functions of tPA, and probably uPA, in CSF.

$(\mathfrak{F}$ Clin Pathol 1997;50:157-160)

Keywords: cerebrospinal fluid; neurological disease; plasminogen activator inhibitor-1.

Plasminogen activator inhibitor-1 (PAI-1), a 50 $\mathrm{kDa}$ serpin protease inhibitor, is a major inhibitor of tissue-type (tPA) and urokinasetype (uPA) plasminogen activators. ${ }^{1-3}$ PAI-1 regulates fibrinolysis and tumour invasion. Plasminogen activators have been associated with a number of biological processes including fibrinolysis and thrombolysis, cell migration, tissue invasion by both normal and malignant cells, and tissue remodelling. ${ }^{45}$ The reaction of PAI-1 with its substrate leads to its inactivation and the formation of an equimolar complex. ${ }^{6}$ Endothelial cells, ${ }^{78}$ among other cell types, and neural tumours, such as the glioblastomas, ${ }^{9-11}$ synthesise and secrete PAI-1, the synthesis of which is regulated by cytokines which are active in the brain in various diseases. ${ }^{12-15}$ Assays of PAI-1 are clinically useful as an increased plasma concentration ${ }^{16}{ }^{17}$ is an important cause of impaired fibrinolytic function, and is associated with thrombotic diseases. ${ }^{18-20}$ Raised plasma concentrations of PAI-1 have been reported in infections ${ }^{21}$ and during pregnancy, ${ }^{22}$ whereas raised cerebrospinal fluid (CSF) concentrations have been reported in some neurological diseases. ${ }^{23}$ The roles of plasminogen activators and plasminogen activator inhibitors (PAI-1 and PAI-2) in the pathogenesis of neurological disease and tumour development have been suggested. ${ }^{23-26}$ In a previous study, we reported a spectacular increase in tPA activity in some neurological diseases, especially in multiple sclerosis. ${ }^{27}$

Here, we report the PAI- 1 concentrations in patients with multiple sclerosis, encephalitis, viral meningitis, and leukaemia in comparison with reference subjects without neurological disease.

\section{Methods}

The procedures followed were in accord with the Helsinki Declaration (revised 1983) for human experimentation. The study population comprised 51 patients undergoing spinal taps for clinical reasons, from whom about $1 \mathrm{ml}$ CSF was drawn into plain bijou bottles. Only samples which were clear and free of blood cells were studied. Blood $(2.5-3 \mathrm{ml})$ was collected by venepuncture from eight of the patients into tubes containing EDTA. All samples were collected between 1200 and 1400 hours. Blood samples were centrifuged at $500 \times g$ for 10 minutes and the plasma stored frozen at $-20^{\circ} \mathrm{C}$ pending analysis. The patients' age ranged from newborn to 77 years. Subjects without neurological disease $(n=20)$ were included as controls. The patient group comprised three patients with viral meningitis, 20 with encephalitis, 19 with multiple sclerosis, seven with acute lymphoblastic leukaemia (ALL) and two with acute myeloid leukaemia (AML) with central nervous system (CNS) 
involvement. CSF tPA and uPA activities in these patients and controls have been reported previously. ${ }^{27}$

\section{CSF ASSAY}

Samples were thawed and assayed for PAI-1 using an enzyme linked immunosorbent assay (ELISA) as recommended by the manufacturer (Monozyme, Hørsholm, Denmark). The assay detected both free (active) and complexed (inactive) PAI-1. Concentrations of PAI-1 were measured by comparing the absorbance for each well with a series of absorbance values obtained from known plasma concentrations of PAI-1, plotted as a standard curve. The standard plasma, provided by the manufacturer, at a concentration of $8 \mathrm{ng} / \mathrm{ml}$ was diluted with the appropriate buffer to cover the range $800 \mathrm{pg} / \mathrm{ml}$ to $25 \mathrm{pg} / \mathrm{ml}$. Each assay was run in duplicate and the average of the two measurements was taken as the final result. Whenever available, both CSF and plasma samples were studied. Plasma samples were assayed in the same way as CSF samples.

\section{STATISTICAL ANALYSIS}

Results are reported as mean (SEM). The non-parametric Mann-Whitney U-test was used for the comparison of means. Correlation coefficients were evaluated according to Pearson. Results were considered significant when $\mathrm{p} \leq 0.05$.

\section{Results}

The assay detected both free PAI-1 and PAI-1protein complexes-that is, total PAI-1. Significantly higher mean PAI-1 concentrations were detected in patients with leukaemia $(p=0.022)$, encephalitis $(p=0.002)$ and multiple sclerosis $(p=0.048)$. The highest mean (SEM) PAI-1 concentration was found in patients with leukaemia $(1.28(0.36) \mathrm{ng} / \mathrm{ml})$, and the next highest in those with encephalitis (1.19 (0.20) $\mathrm{ng} / \mathrm{ml})$. PAI-1 concentrations in patients with meningitis were not significantly different from those in the controls (table 1; figs 1 and 2). PAI-1 concentrations were higher in patients with leukaemia (specifically ALL) and encephalitis, than in those with viral meningitis. There was no association between CSF PAI-1 concentrations and age or uPA activities in either patients or controls. The patients with high PAI-1 concentrations in this study also had high uPA activities in a previous study ${ }^{27}$ and in the same order-leukaemia > encephalitis $>$ multiple sclerosis. We observed a significant negative association between CSF and

Table 1 CSF PAI-1 concentrations and p values in comparison with reference subjects (mean (SEM))

\begin{tabular}{ll}
\hline Subject group & CSF PAI-1 (ng/ml) \\
\hline Leukaemia $(\mathrm{n}=9)$ & $1.28(0.36)^{\star}$ \\
ALL $(\mathrm{n}=7)$ & $1.53(0.42)^{\star \star}$ \\
AML $(\mathrm{n}=2)$ & $0.42(0.05)$ \\
Encephalitis $(\mathrm{n}=20)$ & $1.19(0.20)^{\star \star}$ \\
Multiple sclerosis $(\mathrm{n}=19)$ & $0.65(0.05)^{\star}$ \\
Meningitis $(\mathrm{n}=3)$ & $0.39(0.11)$ \\
Reference subjects $(\mathrm{n}=20)$ & $0.31(0.06)$ \\
\hline
\end{tabular}

${ }^{\star} \mathrm{p}<0.05 ;{ }^{\star \star} \mathrm{p}<0.01$.

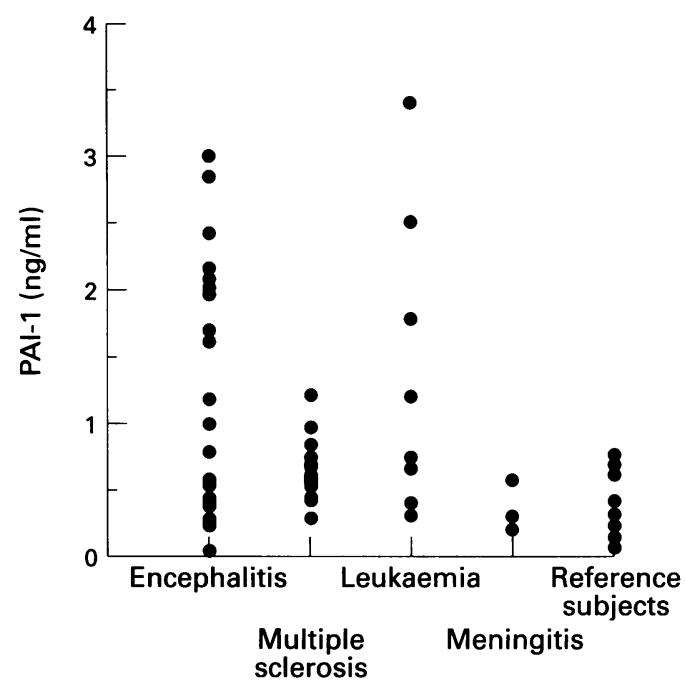

Figure 1 Scattergram showing concentrations of CSF PAI-1.

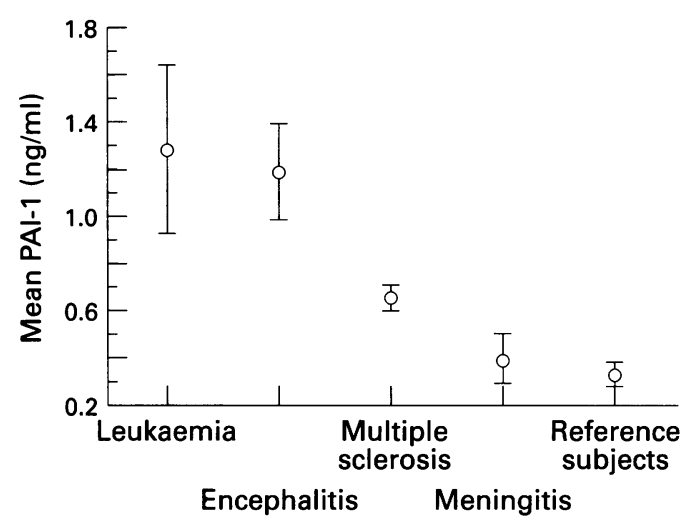

Figure 2 Plot showing mean concentrations of CSF PAI-1.

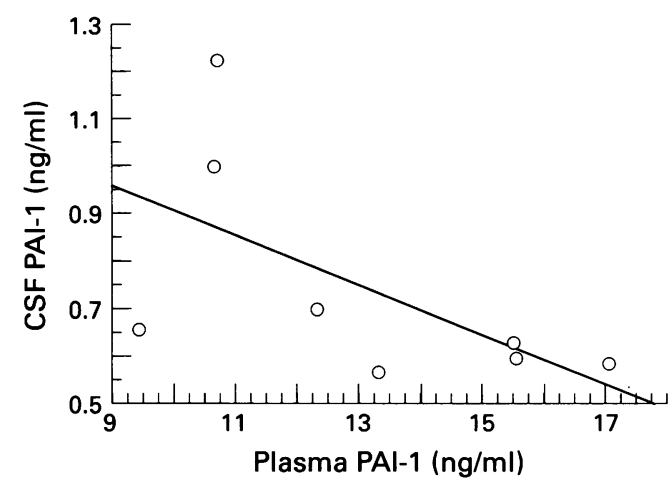

Figure 3 Regression plot of CSF PAI-1 concentrations against plasma PAI-1 concentrations in patients with multiple sclerosis $(p<0.05 ; r=-0.60)$.

plasma ( $n=8)$ PAI-1 concentrations in patients with multiple sclerosis $(p<0.05$; $r=-0.60$ ) (fig 3). There was a non-significant negative association between total CSF PAI-1 concentrations and tPA activity both in patients and controls (for multiple sclerosis $\mathrm{p}=0.36 ; \mathrm{r}=-0.22$ ).

\section{Discussion}

PAI-1 is a major regulator of fibrinolysis in plasma. ${ }^{1-3}$ Increased plasma PAI-1 activity has been reported in various thrombotic disorders. ${ }^{18-20}$ In this study, we observed raised CSF PAI-1 concentrations in patients with 
ALL, encephalitis and multiple sclerosis. In multiple sclerosis, the myelin sheaths surrounding nerves in the brain and spinal cord are damaged, affecting the function of the nerves involved. The disease affects different parts of the brain and spinal cord, resulting in scattered symptoms. In a previous study, ${ }^{27}$ we reported raised CSF tPA activities in patients with multiple sclerosis, leukaemia and encephalitis, with mean activities in decreasing order. PAI-1 concentrations in the same patients were the reverse of their corresponding tPA activities, being higher in those with leukaemia and encephalitis, than in the patients with multiple sclerosis. A significant negative association between TPA and PAI-1 activities has been reported before. ${ }^{28}$ However, the negative association observed in this study was not significant, probably because we measured total PAI-1 (both active and inactive). ${ }^{28}$ This suggests that it is active PAI-1 which is important in regulating tPA activity in both the plasma and CSF. Although high CSF PAI-1 concentrations did not correlate significantly with uPA activities, it is interesting to note that patients with high PAI-1 concentrations in this study also had high uPA activities in a previous study $^{27}$ and in the same order-leukaemia > encephalitis $>$ multiple sclerosis. uPA activity is also known to correlate with PAI-1 expression in malignancy, wound healing and inflammation.

In contrast, there was no difference in the mean concentrations of PAI-1 in patients with viral meningitis compared with controls. The highest PAI-1 concentrations were found in patients with leukaemia, and the next highest in those with encephalitis. Mean PAI-1 concentrations in patients with ALL (with CNS involvement) and encephalitis were significantly higher than in those with meningitis.

CSF PAI-1 may be derived from either the plasma or the brain, or both. Various active and passive mechanisms transport substances across the blood-brain barrier. The concentration of PAI-1 in plasma is at least 20 -fold higher than that in the $\mathrm{CSF}^{29}$ In the event of damage to the blood-brain barrier, as is the case in encephalitis, substances to which the barrier was impermeable to previously can now cross. ${ }^{30}$ This probably explains the raised PAI-1 concentrations encountered in patients with encephalitis and the normal concentrations observed in those viral meningitis, despite the fact that both are inflammatory diseases. We observed a significant negative association between CSF and plasma PAI-1 concentrations in patients with multiple sclerosis $(p<0.05 ; r=-0.60)$. This suggests that, at least in multiple sclerosis, PAI-1 may not cross the barrier by passive transport alone. Plasma samples were not available for the other patient groups or the controls.

It has been suggested that, at least in normal subjects, PAI- 1 is secreted by the choroid plexus together with minute levels synthesised by the CNS and secreted into the CSF. ${ }^{31}$ The increase in PAI-1 concentrations in neurological infections may also be because PAI- 1 is part of the acute phase response, ${ }^{14}$ and in plasma, the presence of bacterial wall lipopolysaccharide induces PAI-1 activity. ${ }^{32}$ Neoplastic astrocytes have also been reported to secrete PAI-1..$^{9-11}$

The highest mean PAI-1 concentration was recorded in patients with ALL. These raised PAI-1 concentrations may be a reflection of the level of CNS involvement. In a study of cell homogenates, however, significantly higher levels of PAI-1 antigen were detected in patients with AML than in those with ALL. ${ }^{33}$

In conclusion, CSF PAI-1 concentrations are raised in various neurological conditions and therefore cannot be used as a diagnostic parameter, although they may be a useful marker for monitoring prognosis.

We wish to thank Ms Satu Mustjoki and Dr Leena Riittinen fo useful discussion, and Kari Asikainen for assistance during data useful disct

analysis.

This work was supported in part by the University of Helsinki, Finland, and the Medical Research Council of the Academy of Finland.

1 Sprengers ED, Kluft C. Plasminogen activator inhibitors Blood 1987;69:381-7.

2 Loskutoff DJ. Type 1 plasminogen activator inhibitor and its potential influence on thrombolytic therapy. Semin Thromb Hemost 1988;14:100-9.

3 Kruithof EKO. Plasminogen activator inhibitors-a review. Enzyme 1988;40:113-21.

4 Danø K, Andreasen PA, Grøndahl-Hansen J, Kristensen K, Nielsen L, Skriver L. Plasminogen activators, tissue degradation and cancer. Adv Cancer Res 1985;44:139-266.

5 Pöllänen J, Stephens RW, Vaheri A. Directed plasminogen activation at the surface of normal and malignant cells. $A d v$ Cancer Res 1991;57:273-328.

6 Andreasen PA, Georg B, Lund LR, Riccio A, Stacey SN Plasminogen activator inhibitors: hormonally regulated serpins. Mol Cell Endocrinol 1990;88:1-19.

7 Loskutoff DJ, Edgington TS. Synthesis of a fibrinolytic activator and inhibitor by endothelial cells. Proc Natl Acad Sci vSA 1977;74:3903-7.

8 Simpson AJ, Booth NA, Moor NR, Benneth B. Distribution of plasminogen activator inhibitor (PAI-1) in tissue. $\mathcal{f}$ Clin Pathol 1991;44:139-43.

9 Caccamo DV, Keohane ME, McKeever PE. Plasminogen activators and inhibitors in gliomas: an immunohistochemical study. Mod Pathol 1994;7:99-104.

10 Kono S, Rao JS, Bruner JM, Sawaya R. Immunohistochemical localization of plasminogen activator inhibitor type 1 in human brain tumours. $\mathcal{F}$ Neuropathol Exp Neurol 1994;53: 256-62.

11 Yamamoto M, Sawaya R, Mohanam S, Bindal AK, Bruner $\mathrm{JM}$, Oka $\mathrm{K}$, et al. Expression and localization of urokinasetype plasminogen activator in human astrocytomas in vivo. Cancer Res 1994;54:3656-61.

12 Sawey M, Podor TJ, Loskutoff DJ. Regulation of type 1 plasminogen activator inhibitor gene expression in cultured bovine aortic endothelial cells. Induction by transforming
growth factor- $\beta$, lipopolysaccharide, in tumour necrosis growth factor- $\beta$, lipopolysaccharide, in tu
factor- $\alpha$. $₹$ Biol Chem 1989;264:10396-401.

13 Laiho $M$, Saksela O, Keski-Oja J. Transforming growth factor- $\beta$ induction of type 1 plasminogen activator inhibitor. F Biol Chem 1987;262:17467-74.

14 De Boer JP, Abbink JJ, Brouwer MC, Meijer C, Roem D, Voorn GP, et al. PAI-1 synthesis in the human hepatoma cell line Hep-G is increased by cytokines-evidence that the liver contributes to acute phase behaviour of PAI-1. Thromb Haemost 1991;65:181-5.

15 Morganti-Korsmann MC, Kossman T, Wahl SM. Cytokines and neuropathology. Trends Pharmacol 1992;13:286-91.

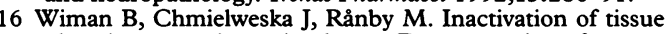
plasminogen activator in plasma. Demonstration of a complex with a new rapid inhibitor. $\mathcal{F}$ Biol Chem 1984;259: 3644-7.

17 Kruithof EKO. Demonstration of a fast acting inhibitor of plasminogen activators in human plasma. Blood 1984;64: 907-13.

18 Wiman B. The role of the fibrinolytic systems. f Lab Clin Med 1985;105:265-70.

19 Hamsten A, Wiman B, De Faire U, Blombäck M. Increased plasma levels of rapid inhibitor of tissue plasminogen activator in young survivors of myocardial infarction. $N$ Engl $\mathcal{F}$ Med 1985;313:1557-63.

20 Isacsson S, Nilsson IM. Defective fibrinolysis in blood and vein walls in recurrent "idiopathic" venous thrombosis. vein walls in recurrent idiopathic

21 Colucci M, Paramo JA, Collen D. Generation in plasma of a fast-acting inhibitor plasminogen activator in response to

22 Wiman B, Csemiczky G, Marsk L, Robbe H. The fast inhibitor of tissue plasminogen activator during pregnancy. Thromb Haemost 1984;52:124-6. 
23 Sutton R, Keohane ME, Van der Berg SR, Gonias SL. Plasminogen activator inhibitor-1 in the cerebrospinal fluid as an index of neurological disease. Blood Coagul Fibrinolysis 1994;5:167-71.

24 Sawaya R, Rayford A, Kono S, Ang KK, Feng Y, Stephens $\mathrm{CL}$, et al. Plasminogen activator inhibitor-1 in the pathogenesis of delayed radiation damage in rat spinal cord in vivo. $\mathcal{F}$ Neurosurg 1994;81:381-7.

25 Gijtenbeek JM, Emeis JJ, Van-der-Sande JJ, Lulf RE. Different types of plasminogen activator activity in human brain tumours: relation with peritumoral oedema? Clin Neurol Neurosurg 1994;96:305-9.

26 De Vries TJ, Mooy CM, Van Balken MR, Luyten GP, Quax $\mathrm{PH}$, Verspaget HW, et al. Components of the plasminogen activation system in uveal melanoma-a clinicoactivation system in uveal melanoma

27 Akenami FOT, Sirén V, Koskiniemi M, Siimes MA Teräväinen $H$, Vaheri A. Cerebrospinal fluid activity of tissue plasminogen activator in patients with neurological diseases. F Clin Pathol 1996;49:577-80.

28 Rånby $\mathrm{M}$, Sundell IB, Nilsson TK. Blood collection in strong acidic citrate anticoagulant used in a study of dietary influence on basal tPA activity. Thromb Haemost 1989;62: 917-22.

29 Kruithof KO, Nicolosa G, Bachmann F. Plasminogen activator inhibitor 1: development of radioimmunoassay and observations on its plasma concentration during venous occlusion and after platelet aggregation. Blood 1987;70:1645-53.

30 Koskiniemi M, Vaheri A, Taskinen E. Cerebrospinal fluid alterations in herpes simplex virus encephalitis. Rev Infect Dis 1984;6:608-17.

31 Rao JS, Chen M, Festoff BW. Plasminogen activator inhibitor 1 , the primary regulator of fibrinolysis, in the normal human cerebrospinal fluid. I Neurosci Res 1993;34:340-5.

32 Emeis JJ, Kooistra T. Interleukin 1 and lipopolysaccharide induce an inhibitor of tissue type plasminogen activator in vivo and in cultured endothelial cells. $f$ Exp Med 1986;163: $1260-6$.

33 Wada H, Kumeda Y, Ogasawara Z, Ohiwa M, Kaneko T, Tamaki S, et al. Plasminogen activators and their inhibitors in leukaemic cell homogenates. Am $\mathcal{F}$ Hematol 1993;42: $166-70$ 